\title{
Investigation on the Performance and Emission Characteristics of Biodiesel (Animal oil) -Ethanol Blends in a Single Cylinder Diesel Engine
}

\author{
[Dr. A. Veeresh Babu, M. Vijay Kumar, Dr. P. Ravi Kumar and Katam Ganesh Babu]
}

\begin{abstract}
Biodiesel is consider as a potential alternative fuel for compression ignition engines. These are obtained from various resources. However, the usage of biodiesel blend in high percentages in compression ignition may cause some technical problems because of their higher viscosity, high pour point, and low volatility. Ethanol can be used as a fuel extender to enable the use of the higher percentage of biodiesel in CI engine. Blends of ethanol-animal fat oil biodiesel-diesel were prepared and experimental studies have been carried out. We have found that B40E20 fuel blend (40\% biodiesel and $20 \%$ ethanol in diesel) reduces the specific fuel consumption and improves brake thermal efficiency of the engine compared to B40 fuel blend. We observed that fuel characteristics improved considerably with the addition of ethanol to biodiesel. Emissions of $\mathrm{CO}, \mathrm{HC}$ and smoke reduced while $\mathrm{CO}_{2}$ emissions were increased due to more complete combustion of the blend.
\end{abstract}

Keywords- Diesel, Biodiesel, Ethanol, CI Engine, Engine Performance, Exhaust Emission.

\section{IV.Introduction}

Biodiesel is a good alternative fuel for diesel engines. It can be directly used in any standard diesel (compressionignition) engine with no modifications and with almost the same performance at any blend level from B1 to B100 since, its molecular similarities with diesel [1]. It is biodegradable, nontoxic and has low emission problems. Hence, it is environmentally beneficial and renewable fuel [2].

Due to its clean emissions profile, ease of use, and many other benefits, biodiesel are quickly becoming one of the fastest growing alternative fuels in the world [3]. With minimal subsidy, biodiesel is cost competitive with petroleum diesel, and millions of users have found and enjoyed the benefits of the fuel. The future of biodiesel lies in the world's ability to produce renewable feed stocks such as vegetable oils and fats to keep the cost of biodiesel competitive with petroleum, without supplanting and necessary for food production, or destroying natural ecosystems in the process. Creating a biodiesel in a sustainable manner will allow this clean, renewable and cost effective fuel to help ease the world through increasing shortages of petroleum [4-5].

\section{A. Biodiesel}

About one-third of the fats and oils produced in the United States are animal fats. This includes beef tallow, pork lard, and chicken fat. Animal fats are attractive feedstock for biodiesel because their cost is substantially lower than the cost of vegetable oil. This is partly because the market for animal fat is much more limited than the market for vegetable oil, much of the animal fat produced, not considered edible in the U.S, currently added to pet food and animal feed, and used for industrial purposes such as soap making. Much of the domestic animal fat has used to export. Animal fats feedstock can be made into high-quality biodiesel that meets the ASTM specifications for biodiesel. However, there are some drawbacks and challenges in using animal fats feedstock.

Animal fats are highly saturated, which means that the fat solidifies at a relatively high temperature. Therefore, biodiesel made from animal fat has a higher cloud point. For example, biodiesel made from beef tallow and pork lard has a cloud point in the range of $55^{\circ} \mathrm{F}$ to $60^{\circ} \mathrm{F}$. B 100 (pure biodiesel) made from animal fat should only be used in a very warm climate. However, animal fat biodiesel can be blended with petroldiesel.

When the animal fat mixed into biodiesel, the concern about solidification at lower temperatures continues. The methyl esters from the saturated fatty acids, mainly methyl stearate and methyl palmitate have high melting points. The saturated fatty acids in animal fats should contribute to the better oxidative stability of biodiesel. Animal fats contain very little of the polyunsaturated fatty acids, such as linoleic acid and linolenic acid, that make vegetable oils such as soybean oil and linseed oil so prone to rancidity.

However, in practice animal fat is not always more stable than vegetable oil, because vegetable oils often contain natural anti-oxidants. For example, a test of the peroxide content of lard and vegetable oil showed that the lard experienced oxidation faster than the vegetable oil [6]. Viscosity and density of biodiesel produced from animal fat has found to be very close to that of diesel. Its calorific value has found to be slightly lower than that of diesel [7]. It has some advantages such as high Cetane number, non-corrosive, clean and renewable properties. From these advantages, the animal oil has selected for investigation in CI engines.

\section{B. Additive}

There are certain disadvantages of biodiesel, which include the higher viscosity and pour point, as well as the lower calorific value and volatility. For all above reasons, it is generally not accepted more than $20 \%$ biodiesel blend in existing diesel engines without any modifications. Consequently, in many cases the presence of a solvent additive in the biodiesel blend becomes necessary. It is well proved that ethanol can be used as a fuel for SI engines. Many countries have implemented ethanol successfully. This ethanol 
can be produced from ethylene, corn, sugar beets, sugar cane, or even cellulose.

Ethanol can also use as a fuel in CI engine. Various techniques have developed to introduce ethanol into a compression ignition engine. However, the use of ethanoldiesel blends, usually named as e-diesel, has also some limitations. It has a lower viscosity and lower lubrication property, reduced ignition ability and Cetane number, higher volatility and lower miscibility that may lead to increased unburned hydrocarbons emissions [8-12]. It was observed that engine performance with methyl ester and ethanol blends had similar to that with diesel. However, specific fuel consumption has increased about $10 \%$ with use of ethanol- methyl ester blend than that of diesel. Blending ethanol with biodiesel had the advantage of reducing the viscosity [13] as well as reducing crystallization of biodiesel. However, not much research has been available on ethanol biodiesel blend as a fuel.

The main objective of this study is to improve the fuel characteristics of biodiesel by using a fuel extender to utilize more percentage of biodiesel in diesel engines. The ethanol has selected for this purpose. Animal fats offer the advantage of freely mixing with alcohols (both methanol and ethanol), and these blends can be used in the existing diesel engines without modifications. This is a simple process. The major advantages of the blending are the absence of technical modifications and the ease of implementation. In this work the performance, and exhaust emissions of biodiesel derived from animal fat blended with ethanol-diesel were investigated in a single cylinder, four stroke cycle, and direct injection diesel engine. Experimental results has compared with those of standard diesel fuel.

\section{V.Transesterification process}

The chemical conversion of the oil to its corresponding fatty ester (biodiesel) is known as transesterification. In this process, vegetable oil or animal fat is filtered and processed with methanol - alkali to remove free fatty acid. The chemical reaction of transesterification has shown in below Fig.2.1.

Once the reaction is complete, two major products exist: glycerin and biodiesel. Each has a substantial amount of excess methanol that has used in the reaction. The reaction mixture sometimes neutralized at this step, if needed. The glycerin phase is much denser than the biodiesel phase and the two can be gravity separated with glycerin simply drawn off the bottom of the settling vessel. In some cases centrifuge used to separate the two materials faster.

After separating from glycerin, the biodiesel has purified by washing gently with warm water for the removal residual catalyst or soaps. This is normally the end of production process resulting in clear amber yellow liquid.

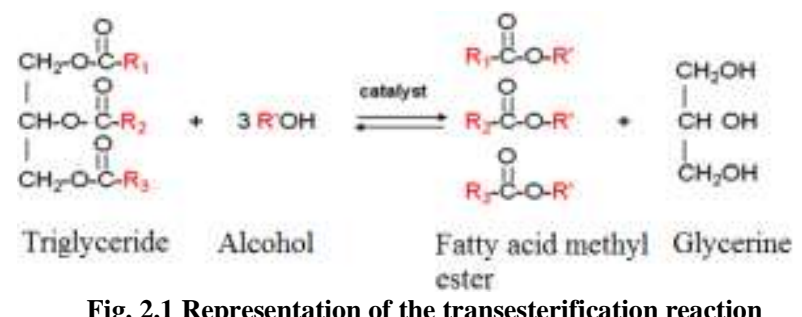

\section{VI.Fuel properties}

Various physical properties of the diesel, biodiesel, biodiesel-diesel blends (B20 and B40) and biodiesel-dieselethanol blend (B40E20) like kinematic viscosity, dynamic viscosity, density, flash point, fire point were measured in the laboratory. The major properties of the fuels are shown in Table 3.1.
TABLE 3.1
TABLE TYPE STYLES

\begin{tabular}{|l|c|c|c|c|c|}
\hline \multicolumn{1}{|c|}{ Properties } & Diesel & $\begin{array}{c}\text { Animal Fat } \\
\text { biodiesel }\end{array}$ & B20 & B40 & B40E20 \\
\hline Density $\left(\mathrm{kg} / \mathrm{m}^{3}\right)$ & 831 & 867 & 838 & 845 & 841 \\
\hline $\begin{array}{l}\text { Kinematic } \\
\text { viscosity }(\mathrm{CST})\end{array}$ & 2.89 & 4.86 & 3.36 & 3.95 & 3.31 \\
\hline Flash Point $\left({ }^{0} \mathrm{C}\right)$ & 50 & 125 & - & - & - \\
\hline Fire Point $\left({ }^{0} \mathrm{C}\right)$ & 56 & 145 & - & - & - \\
\hline $\begin{array}{l}\text { Calorific value } \\
(\mathrm{kJ} / \mathrm{kg})\end{array}$ & 42700 & 38450 & 41850 & 41000 & 38400 \\
\hline
\end{tabular}

Note: "_" means not measured

\section{VII.Experiment setup and procedure}

\section{A. Engine test}

A single cylinder four-stroke water-cooled diesel engine developing a power output of $3.7 \mathrm{~kW}$ i.e. $5 \mathrm{HP}$ at rated speed of $1500 \mathrm{rev} / \mathrm{min}$ has selected for the work. The specifications of the engine are shown in Table 4.1. The Schematic of the experimental setup is shown in Fig. 4.1. A DC shunt dynamometer is used for loading the engine. The fuel flow rate has measured by volume through a burette. The experiment has been conducted to run at constant compression ratio of 16.5:1 and Injection pressure is $200 \mathrm{bar}$.

\section{B. Emission instrumentation}

Smoke opacity of the exhaust gas is measured with the help of Bosch smoke meter. It is filter darkening type smoke meter. In this, a measured volume of exhaust gas is drawn through the filter paper, which is blackened, to various degrees depending on the carbon present in the exhaust gas. The density of soot is measured by amount of light reflected from paper. AVL exhaust gas analyser was used to measure the constituent of $\mathrm{CO}, \mathrm{HC}$ and $\mathrm{CO}_{2}$.

\section{Experimental Procedure}

The engine used to run at a constant speed of $1500 \mathrm{rpm}$ with an attachment of eddy current dynamometer. The $\mathrm{CO}, \mathrm{HC}$ and 


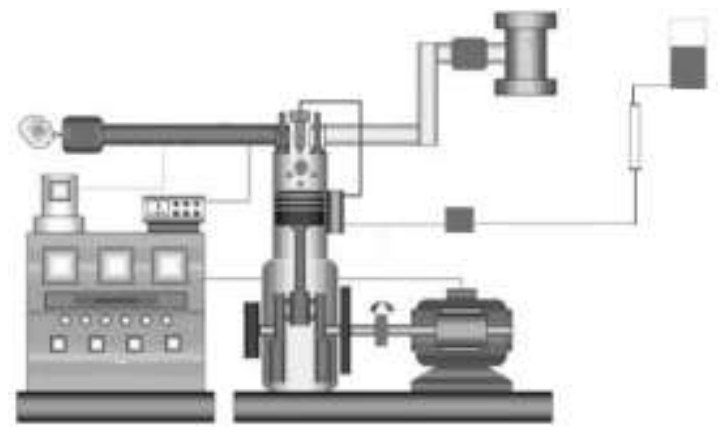

Fig. 4.1. Schematic of experimental setup

TABLE 4. 1 ENGINE SPECIFICATION

\begin{tabular}{|llc|}
\hline 1. Make & $:$ & Kirloskar \\
2. Model & $:$ & AV1 \\
3. No. of cylinder & $:$ & 1 \\
4. Type & $:$ & Direct injection, water cooled, Four \\
stroke \\
5. Bore $\times$ stroke $(\mathrm{mm})$ & $:$ & $80 \times 110$ \\
6. Cubic capacity & $:$ & 0.553 \\
(Litre) & $:$ & $16.5: 1$ \\
7. Compression ratio & $:$ & $3.7 \mathrm{~kW}-5 \mathrm{HP}$ \\
8. Rated power (kW- & $:$ & $1500 \mathrm{rpm}$ \\
HP) & $:$ & Hand start \\
10. Starting & $:$ & $130 \mathrm{~kg}$ \\
11. Engine weight (dry) & $:$ & $200 \mathrm{bar}$ \\
12. Injection pressure & $:$ & Rated
\end{tabular}

$\mathrm{CO}_{2}$ emission were measured with AVL exhaust gas analyser. The gas analyzers were calibrated with standard gases and zero gas periodically. Experiments were conducted at the engine speed of 1500 RPM and at five engine loads. At each engine operating mode, experiments were carried out for the biodiesel (B20, B40), biodiesel-ethanol (BE) namely B40E20. Before each test, it must be ensured that the residual fuel of the previous test in the fuel tank and fuel system has completely removed or consumed by the engine. Even, the engine was allowed to operate with the new fuel till steady conditions has attained. The data were recorded continuously for $5 \mathrm{~min}$ to reduce experimental uncertainties, and average values were recorded. All the performance and emissions characteristics results were plotted and compared for various blends of biodiesel with the help of following graphs.

\section{Results and Discussions}

The performance and emission characteristics of the various load conditions for different fuels are analyzed and the results are presented in the following sections.

\section{A. Brake specific fuel consumption}

The variation of brake specific fuel consumption (BSFC) with load for different fuels has presented in Fig.5.1. For all fuels tested, BSFC is found to decrease with an increase in the load. The BSFC value for B20 and B40 biodiesel was found to be more than diesel fuel by about $7 \%$ and $8 \%$ respectively at $75 \%$ load. More fuel flow rate for the same displacement of the plunger in the fuel injection pump, thereby increasing specific fuel consumption, as the density of animal fat biodiesel was higher than that of diesel fuel [7]. One more reason is the calorific value of animal fat biodiesel, which is 9$10 \%$ less than that of diesel fuel. The lower heating value of biodiesel requires that a more amount of fuel be injected into the combustion chamber to produce the same power.

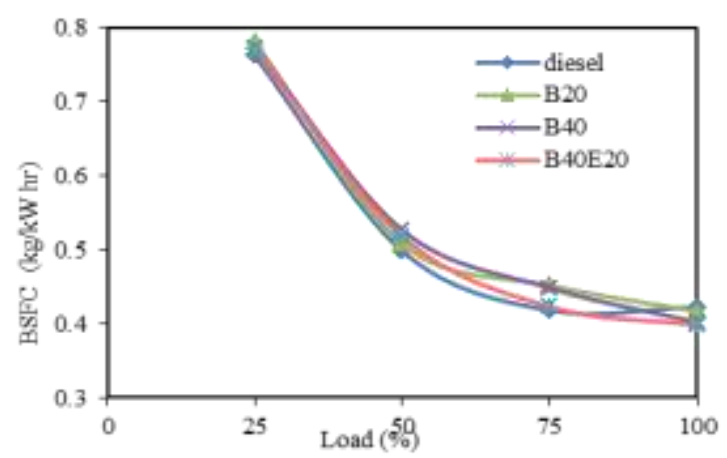

Fig. 5.1 Comparison of brake specific fuel Consumption (BSFC) with load

The fuel viscosity had a great influence on brake specific fuel consumption [13]. By addition of $20 \%$ ethanol in B40E20 fuel, there is decreased viscosity and density of fuel which leads to decreased BSFC results for B40E20 than B40 blend. The lower calorific value of the B40E20 fuel is probably compensated by the better atomization of the fuel in the combustion chamber.

\section{B. Brake thermal efficiency}

The variation of Brake thermal efficiency (BTE) with load for different fuels is presented in Fig.5.2. In all cases, brake thermal efficiency has the tendency to increase with increase in applied load. This is due to the reduction in heat loss and increase in power developed with increase in load.

It can be seen from the figure, that the thermal efficiency of diesel fuel is highest and it was decreased for B40 and B20 biodiesel fuel. The mean thermal efficiency for B20, B40 was less than that of diesel fuel by about $10 \%$, and $7.6 \%$, respectively. The animal fat methyl ester has a higher viscosity, density and lower heat value than the diesel fuel. The higher viscosity leads to poor atomization, fuel vaporization and combustion, and hence the thermal efficiency of biodiesel are lower than that of diesel fuel. Fuel consumption increases due to higher density and lower heating value consequently, thermal efficiency decreases.

The brake thermal efficiency of B40E20 fuel is on par with that of standard diesel fuel. The combined effects of higher oxygen content, and improved spray characteristics due to lower viscosity may result in a higher burning rate of the blend, which result in higher efficiency. Average brake thermal efficiency of B40E20 is higher by $8.6 \%$ than that of B40 fuel. 


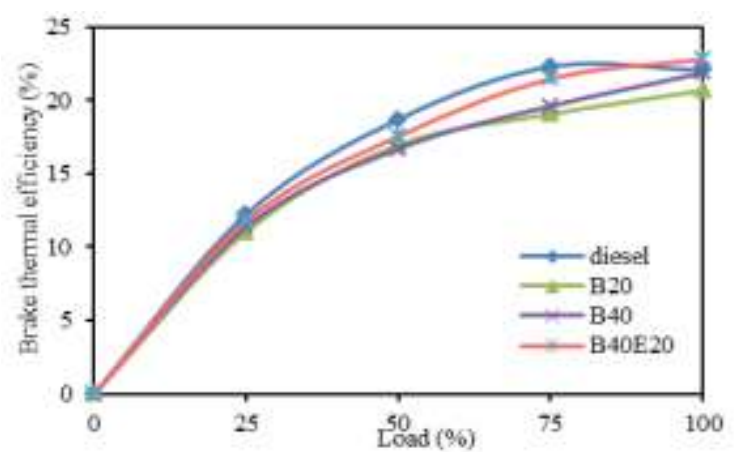

Fig. 5.2 Comparison of brake thermal efficiency with load

\section{HC emissions}

The unburned hydrocarbon variations with load for different fuels has presented in Fig.5.3. As the load increases, unburned $\mathrm{HC}$ emissions decrease for all of the cases due to the increase in combustion temperature associated with higher engine load.

It has observed that biodiesel fuel blends show lower emissions than that of diesel fuel. Average emissions of B20 and B40 blends were lower by $26 \%$ and $22 \%$ than that of diesel. The possible reason is oxygen content in the biodiesel, which leads to a more complete and cleaner combustion. In addition to above, the higher Cetane number of biodiesel reduces the combustion delay, and such a reduction in $\mathrm{HC}$ emissions.

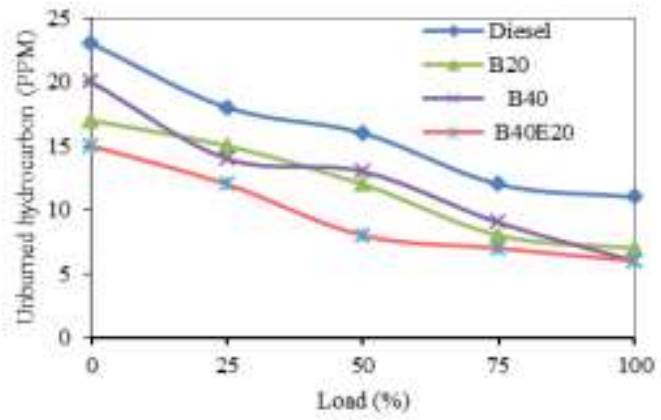

Fig. 5.3 Comparison of Unburned hydrocarbon emissions with load When ethanol had added as an additive, the present work shows considerable decrease in $\mathrm{HC}$ emissions for B40E20 fuel, almost about $40 \%$ lower than diesel fuel. This could be due to increased oxygen content leads to better combustion, and lower viscosity leads to better fuel atomization. Improved spray characteristics improves the combustion and decreased emissions

\section{Carbon monoxide emissions}

The variations of $\mathrm{CO}$ emissions with load for different test fuels has presented in Fig. 5.4. It can be observed that both biodiesel-diesel blend and biodiesel-diesel-ethanol blend shows lower $\mathrm{CO}$ emissions than that of standard diesel fuel. The possible reason for this decrease in emissions is more oxygen content of biodiesel and its blends. In addition, it is likely that biodiesel has $\mathrm{C} / \mathrm{H}$ ratio that is less than for diesel fuel [14]. Because of this reason, diesel fuel has highest value especially at mid ranges of loads. Also observed that $\mathrm{CO}$ emissions trend is not linear. CO formation has significantly affected by in-cylinder temperature. When the fuel blends are used, the combustion process can be dissimilar for different tests [14], therefore; performance and emissions results can be different. In the figure, it has observed that emissions of B20 fuel are higher at lower and higher loads. The temperature can cause this result.

Lowest emissions of $\mathrm{CO}$ is caused due to the enrichment of oxygen owing to the ethanol addition. An increase in the proportion of oxygen will promote the further oxidation of $\mathrm{CO}$ during the engine exhaust process.

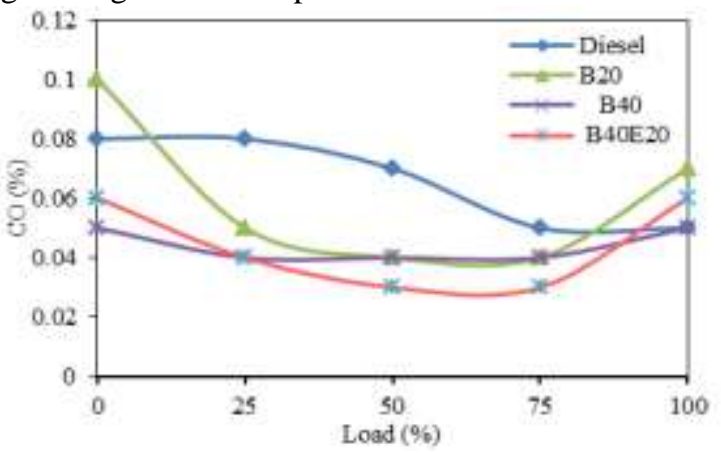

Fig. 5.4 Comparison of Carbon monoxide emissions with load

\section{E. Carbon dioxide emissions}

The variation of $\mathrm{CO}_{2}$ emissions with load for different test fuels has presented in Fig. 5.5. The higher $\mathrm{CO}_{2}$ for B40E20 fuel and diesel fuels for most of the load ranges explains that combustion is more complete for both mentioned fuels. Average $\mathrm{CO}_{2}$ emission of $\mathrm{B} 40 \mathrm{E} 20$ fuel is $3.6 \%$ more than that of B40 fuel. Oxygen enrichment and better combustibility due to lower viscosity are the reason behind it. In general, average emissions of biodiesel and biodiesel-ethanol blends are considerably less than that of standard diesel fuel.

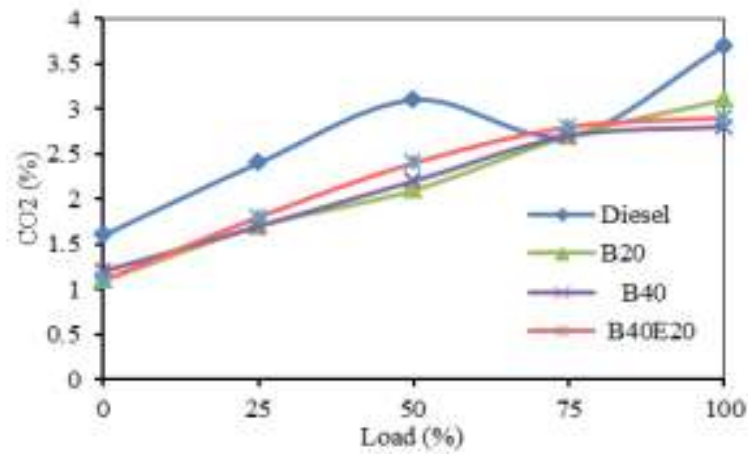

Fig. 5.5 Comparison of Carbon dioxide emissions with load

\section{F. Smoke emissions}

The variation of smoke emissions with load for different test fuels has presented in Fig. 5.6. The smoke emissions were less than for the diesel fuel. The difference is significant, especially at higher loads. Smoke levels are high at high power outputs. This is due to the presence of fuel rich core at high loads [7]. 
The average smoke for B20, B40, and B40E20 were less than that of diesel fuel by $24.4 \%, 44 \%, 42.4 \%$, respectively. The smoke reduction is explained by oxygen content in the biodiesel that contributed for complete fuel oxidation. The more carbon a fuel molecule contains, the more likely to produce soot. Conversely, oxygen within a fuel decreases the tendency of a fuel to produce soot. For most of the load ranges smoke emissions of B40E20 fuel are less than that of B40 fuel. The possible reason is that ethanol acts as an oxidizer in the fuel rich regions that suppresses soot formation in the combustion chamber. At higher loads smoke emissions of B40E20 increases slightly; this may be due to some incomplete combustion at high loads.

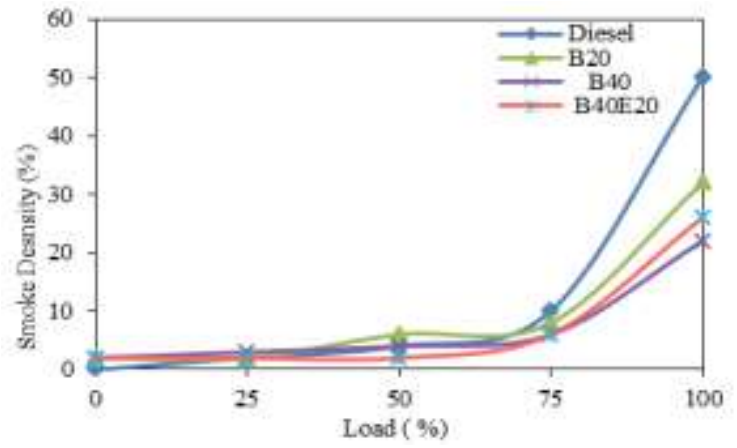

Fig. 5.6 Comparison of Smoke emissions with load

\section{VI.Conclusions}

During the investigations several tests were carried out on a four stroke, single vertical cylinder, water cooled, direct injection diesel engine using diesel, blends of diesel with animal fat biodiesel, and with animal fat biodiesel-ethanol additive. From the experimentation following conclusions were drawn.

- Viscosity and density of animal fat biodiesel are found to meet ASTM D 6751 specifications.

- Blends of biodiesel-ethanol-diesel can be made easily and these blends can be used in the existing diesel engines.

- BSFC of B40 and B20 blends are found to be highest among all the blends. Ethanol as an additive reduces BSFC and it is almost equal to diesel fuel.

- Significant increase in efficiency can be found with B40E20 fuel. It can be concluded that ethanol addition improves fuel characteristics of biodiesel.

- Lowest CO emissions are observed in case of B40E20 fuel, especially at higher loads, indicates complete combustion of fuel.

- Considerable decrease in unburned hydrocarbon emissions for B40E20 fuel, almost 40\% lower than that of diesel fuel.

- $\mathrm{CO}_{2}$ emissions of both diesel and B40E20 fuel are higher.

- B40E20 smoke emissions were lower than that of B40 for most of the load range.

\section{References}

[1] Ayhan Demirbas, "Importance of biodiesel as transportation fuel," Energy Policy, 35 (2007), 4661-4670.
[2] Magi'n Lapuerta, Octavio Armas, Jose' Rodri'guez, "Effect of biodiesel fuels on diesel engine emissions," Progress in Energy and Combustion Science, 34 (2008), 198-223.

[3] A. Murugesan, C. Umarani, R. Subramanian, N. Nedunchezhian, "Biodiesel as an alternative fuel for diesel engines," Renewable and Sustainable Energy Reviews, 13 (2009), 653-662.

[4] Mustafa Balat, "Potential alternatives to edible oils for biodiesel production," Energy Conversion and Management, 52 (2011), 14791492.

[5] Nadir Yilmaz, "Comparative analysis of biodiesel-ethanoldieselandbiodiesel-methanol-diesel blends in a diesel engine," Energy 40 (2012), 210-213.

[6] Stuckey, Ben N. (1972). "Antioxidants as Food Stabilizers," in Handbook of Food Additives 2nd edition, ed. Thomas Furia. Cleveland, OH: CRC Press.

[7] M. Senthil Kumar, A. Kerihuel, J. Bellettre, M. Tazerout, "Ethanol animal fat emulsions as a diesel engine fuel," - Part 2: Engine test analysis, Fuel, 85 (2006), 2646-2652.

[8] Huseyin Aydin, Cumali Ilkilic, "Effect of ethanol blending with biodiesel on engine performance and exhaust emissions in a CI engine, Applied Thermal Engineering," 30 (2010), 1199-1204.

[9] Eloisa Torres-Jimenez, Marta Svoljšak Jerman, Andreja Gregorc, Irenca Lisec, M. Pilar Dorado, Breda Kegl, "Physical and chemical properties of ethanol-diesel fuel blends," Fuel, 90 (2011), 795-802.

[10] Nadir Yilmaz, Tomas M. Sanchez, "Analysis of operating a diesel engine on biodiesel-ethanol and biodiesel-methanol blends," Energy, 46 (2012), 126-129.

[11] Nadir Yilmaz, Francisco M. Vigil, A. Burl Donaldson, Tariq Darabseh, "Investigation of CI engine emissions in biodiesel-ethanol-diesel blends as a function of ethanol concentration," Fuel, 115 (2014), 790-793.

[12] Mário L. Randazzo, José R. Sodré, "Exhaust emissions from a diesel powered vehicle fuelled by soybean biodiesel blends (B3-B20) with ethanol as an additive (B20E2-B20E5)," Fuel, 90 (2011), 98-103.

[13] Dung Nguyen and Damon Honnery, "Combustion of bio-oil ethanol blends at elevated pressure," Fuel, vol. 87, pp.232-243, 2008.

[14] Cengiz Oner, Sehmus Altun, "Biodiesel production from inedible animal tallow and an experimental investigation of its use as alternative fuel in a direct injection diesel engine, " Applied Energy, 86 (2009), 2114-2120.

[15] K. Anand, R.P. Sharma, Pramod S. Mehta, "Experimental investigations on combustion, performance and emissions characteristics of neat karanja biodiesel and its methanol blend in a diesel engine, biomass and bio energy," 35 (2011), 533-541.

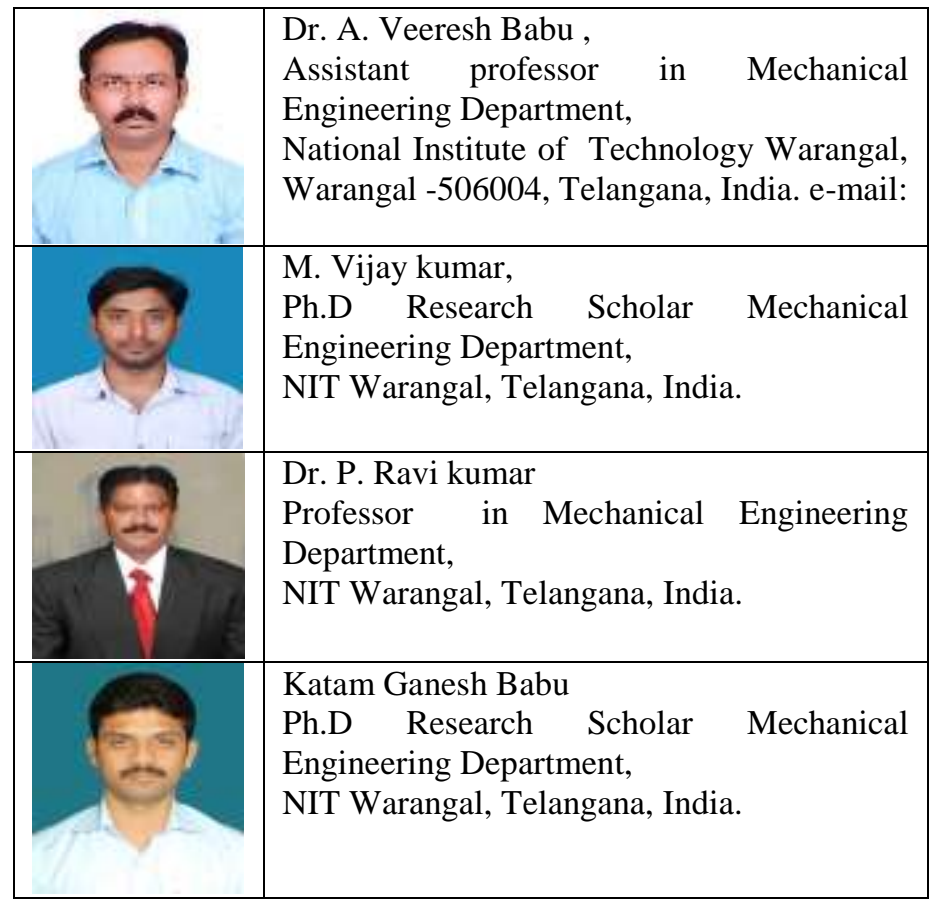

